\title{
Rapid root assimilation of added phosphorus in a lowland tropical rainforest of French Guiana
}

Leandro Van Langenhove ${ }^{1 *}$, Ivan A. Janssens, ${ }^{1}$ Lore Verryckt, ${ }^{1}$ Laetitia Brechet, ${ }^{1}$ lain P. Hartley ${ }^{2}$, Clement Stahl $^{3}$, Elodie Courtois ${ }^{4}$, Ifigenia Urbina ${ }^{5,6}$, Oriol Grau ${ }^{5,6,7}$, Jordi Sardans ${ }^{5,6}$, Guille Peguero ${ }^{1}$, Albert Gargallo-Garriga ${ }^{5,6,8}$, Josep Peñuelas ${ }^{5,6}$, Sara Vicca ${ }^{1}$

${ }^{1}$ Centre of Excellence PLECO (Plants and Ecosystems), Department of Biology, University of Antwerp, Wilrijk, Belgium

${ }^{2}$ Department of Geography, University of Exeter, RennesDrive, Exeter, Devon EX4 4RJ, United Kingdom

${ }^{3}$ INRA, UMR EcoFoG, CNRS, Cirad, AgroParisTech, Université des Antilles, Université de Guyane, Kourou, France

${ }^{4}$ Laboratoire écologie, évolution, interactions des systèmes amazoniens (LEEISA), Université de Guyane, CNRS, IFREMER, Cayenne, France

${ }^{5}$ CSIC, Global Ecology Unit CREAF-CSIC-UAB, Cerdanyola del Vallès, Catalonia 08193, Spain

${ }^{6} \mathrm{CREAF}$, Cerdanyola del Vallès, Catalonia 08193, Spain

${ }^{7}$ Cirad, UMR EcoFoG (AgroParisTech, CNRS, Inra, Univ Antilles, Univ Guyane), Campus Agronomique, 97310 Kourou, French Guiana

${ }^{8}$ Global Change Research Institute, Czech Academy of Sciences, Czechia

*Correspondence to leandro.vanlangenhove@uantwerpen.be

\section{Abstract}

Tree growth on weathered soils in lowland tropical forests is limited by low phosphorus $(P)$ availability. However, nutrient manipulation experiments do not always increase the $\mathrm{P}$ content in these trees, suggesting that they have strategies to acquire $P$ from their environment. In French Guianese lowland rainforest, we measured changes in nitrogen $(\mathrm{N})$ and $\mathrm{P}$ availability before and up to two months after $\mathrm{N}$ and $\mathrm{P}$ fertilizer addition, in soils with intact root systems and in soils where roots and mycorrhizal fungi were excluded by root exclusion cylinders. When the root system was excluded, $\mathrm{P}$ addition increased $\mathrm{P}$ availability to a much greater extent and for a longer time than in soils with an intact root system. Soil $\mathrm{N}$ dynamics were unaffected by root presence/absence. These results are evidence of rapid $\mathrm{P}$ uptake, but not $\mathrm{N}$ uptake, by tree roots, suggesting a very effective $\mathrm{P}$ acquisition process in these lowland rainforests.

\section{Keywords}

Tropical Forest, Phosphorus, Nitrogen, Fertilization, Root System, Plant Root Simulator Probes 
1 A long-standing paradigm in terrestrial ecology is that tropical forest productivity is limited by 2 phosphorus (P) availability (Vitousek, 1984; Vitousek and Sanford, 1986) because the strongly weathered soils of the tropics are depleted in P (Walker and Syers, 1976; Wardle et al., 2004). There is a wealth of indirect evidence for $\mathrm{P}$ limitation in tropical forests, including high N:P ratios in leaves and correlations between forest productivity and soil P stocks at continental scale (Quesada et al., 2012; ter Steege et al., 2006). Nutrient addition experiments confirm that soil microbial communities experience $P$ limitation in tropical forests (Camenzind et al., 2018), but these experiments do not always confirm a P limitation in trees (Cleveland et al., 2011; Wright, 2019). The lack of a clear growth response to $\mathrm{P}$ addition in tropical forests on $\mathrm{P}$-poor soils has been taken to suggest that these trees are strongly adapted to the low P conditions (Turner et al., 2018). Still, it is not known whether the added $P$ is quickly occluded in the soil mineral fraction or assimilated by microbes (Olander and Vitousek, 2004), making it unavailable trees, or if trees are very effective in acquiring P (e.g. from dead organic matter) and hence are not experiencing P limitation as suggested by Gill and Finzi (2016).

We used a NxP fertilization experiment in the lowland rainforests of French Guiana to explore the effectiveness of added $P$ uptake by plants. To this end, we assessed the fate of added P fertilizer and compared this to the fate of added $\mathrm{N}$, a nutrient that is usually in ample supply in tropical rainforests (Hedin et al., 2009). We hypothesized that the trees, adapted to low P availability soils, are much more effective in the assimilation of added $\mathrm{P}$ than in the assimilation of added $\mathrm{N}$, which is more abundant in this forest (Van Langenhove et al., 2019). The fertilization experiment started in 2016 at the Paracou research station in French Guiana and consisted of twelve plots that received $a+N,+P,+N P$ or no treatment (control). Soils are highly weathered and have typical characteristics associated with low fertility, such as low cation exchange capacity, high acidity and very low total and available P concentrations (Sabatier et al., 1997; Gourlet-Fleury et al., 2004; Grau et al., 2017; see supplementary text). Due to a sesquioxide dominated mineral fraction and the presence of 1:1 clays such as kaolinite, these soils have a high capacity to adsorb mineral P, reducing its availability to plants (Sposito, 1989).

The large standing forest biomass in the French Guianese lowland rainforest (Gourlet-Fleury et al., 2004) seriously complicates detection of plant nutrient uptake, considering the large and highly variable nutrient stocks in the plant community. In addition, the very high species richness in these forests makes it difficult to replicate the plant community from one plot to the next, so fertilization effects can only be compared among a few common species that are found in multiple plots. Instead of assessing trees directly, we chose to focus on soil nutrient dynamics in presence and absence of the root system. Therefore, we used a root exclusion cylinder (REC) technique (Huang and Schoenau 1997). RECs were PVC collars inserted $20 \mathrm{~cm}$ into the soil to sever all near-surface roots and mycorrhizal hyphae, and were installed in every plot prior to the first nutrient addition in 2016. To follow changes 
in soil $\mathrm{N}$ and $\mathrm{P}$ availability we used commercially available $\mathrm{PRS}^{\mathrm{TM}}$ probes (Western Ag Global, Saskatoon, SK, Canada), which provide proxies for plant available ions in soil solution, including inorganic $\mathrm{N}\left(\mathrm{N}_{\mathrm{i}}\right)$ and inorganic $P\left(P_{i}\right)$, while they are in contact with soil (Qian and Schoenau, 2002). To measure changes in soil $\mathrm{N}_{\mathrm{i}}$ and $\mathrm{P}_{\mathrm{i}}$ availabilities over time, probes were inserted in the soil four times in 2017; one month before fertilization, and four days, four weeks and finally eight weeks after fertilization. Inserting PRS probes both inside and outside the RECs allowed us to assess the differences in $\mathrm{N}_{\mathrm{i}}$ and $\mathrm{P}_{\mathrm{i}}$ availabilities with time in the same soil mass, which either included or excluded roots, following fertilization. With this setup, we were able to account for occlusion of added fertilizer into sesquioxides, occurs rapidly after fertilization (e.g. Olander and Vitousek 2004; Buehler et al., 2002). Details of the methods and statistics are presented in the supplementary text.

After fertilization, the plots receiving additional $\mathrm{N}, \mathrm{P}$ or NP exhibited significant increases in $\mathrm{N}_{\mathrm{i}}$ or $\mathrm{P}_{\mathrm{i}}$ availabilities, respectively, with initial peaks declining over the following two months (Fig 1.). Additionally, in the absence of roots, $\mathrm{P}_{\mathrm{i}}$ availabilities increased more than 10 -fold following $\mathrm{P}$ addition and 3-fold following NP addition (Fig 1B). Root removal can also cause changes in aluminum reactivity (Barra et al., 2018) or microbial biomass (Minz et al., 2013), which may impact $P_{i}$ availability. However, these changes alone are unlikely to explain the large differences in post fertilization $P_{i}$ availability observed between root inclusion and exclusion treatments. If they had a substantial influence, these effects would most likely also be reflected in the control or $+N$ treatment. The difference in $P_{i}$ availability between the P and NP treatments may be related to greater microbial P uptake and growth in the NP treatment (Fanin et al., 2016), but this was beyond the scope of the study. Importantly, in the presence of roots the increases in $\mathrm{P}_{i}$ availability in response to $\mathrm{P}$ and NP addition were significantly smaller (Fig 1A) than in the absence of roots, while for $N_{i}$ the presence or absence of the root system did not affect its availability (Fig $1 \mathrm{C}$ and $\mathrm{D}$ ). The contrasting dynamics of soil $\mathrm{N}$ and $\mathrm{P}$ suggest that the root system rapidly assimilated the added $\mathrm{P}$ while the added $\mathrm{N}$ remained in soil solution even in the presence of roots. This indicates fast and effective plant uptake of added $P$ and most likely implies that the plants in this ecosystem are also very effective in taking up the $P$ that continuously cycles through the forest (Reed et al., 2011). Such effective P uptake could avoid plants running into P limitation, even when soil available $\mathrm{P}$ is low, potentially clarifying the lack of growth response to $\mathrm{P}$ addition in several tropical P addition experiments (see e.g. Wright et al., 2019). Our study further demonstrates that combining a root exclusion technique with a nutrient availability proxy (first demonstrated by Huang and Schoeneau, 1997) can provide new insights into the (rapid) uptake of added nutrients by the root system over time in nutrient addition experiments, and to identify which elements are in greatest demand. This method is particularly valuable in highly diverse, tree-based ecosystems where identifying biomass and nutrient stock changes is a major challenge. 
69 Acknowledgements

70 This research was supported by the European Research Council Synergy grant ERC-2013-SyG. 610028-

71 IMBALANCE-P. We thank the staff of the Paracou station, managed by UMR Ecofog (CIRAD; INRA,

72 Kourou). The research station received support from "Investissement d'Avenir" grants managed by

73 Agence Nationale de la Recherche (CEBA: ANR-10-LABX-25-01,ANAEE France: ANR-11-INBS-0001). 


\section{References}

Barra, P.J., Viscardi, S., Jorquera, M.A., Duran, P.A., Valentine, A.J., de la Luz Mora, M., 2018. Understanding the Strategies to Overcome Phosphorus-Deficiency and Aluminum-Toxicity by Ryegrass Endophytic and Rhizosphere Phosphobacteria. Frontiers in Microbiology 9.

Buehler, S., Oberson, A., Rao, I.M., Friesen, D.K., Frossard, E., 2002. Sequential Phosphorus Extraction of a 33P-Labeled Oxisol under Contrasting Agricultural Systems. Soil Science Society of America Journal 66, 868-877.

Camenzind, T., Hattenschwiler, S., Treseder, K.K., Lehmann, A., Rillig, M.C., 2018. Nutrient limitation of soil microbial processes in tropical forests. Ecological Monographs 88, 4-21.

Cleveland, C.C., Townsend, A.R., Taylor, P., Alvarez-Clare, S., Bustamante, M.M.C., Chuyong, G., Dobrowski, S.Z., Grierson, P., Harms, K.E., Houlton, B.Z., Marklein, A., Parton, W., Porder, S., Reed, S.C., Sierra, C.A., Silver, W.L., Tanner, E.V.J., Wieder, W.R., 2011. Relationships among net primary productivity, nutrients and climate in tropical rain forest: a pan-tropical analysis. Ecol Lett 14, 939947.

Fanin, N., Hattenschwiler, S., Chavez Soria, P.F., Fromin, N., 2016. (A)synchronous Availabilities of N and $\mathrm{P}$ Regulate the Activity and Structure of the Microbial Decomposer Community. Front Microbiol 6, 1507.

Gill, A.L., Finzi, A.C., 2016. Belowground carbon flux links biogeochemical cycles and resource-use efficiency at the global scale. Ecol Lett 19, 1419-1428.

Gourlet-Fleury, S., Guehl, J.M., Laroussinie, O., 2004. Ecology and management of a neotropical rainforest. Lessons drawn from Paracou, a long-term experimental research site in French Guiana. Elsevier, Meppel, The Netherlands.

Grau, O., Penuelas, J., Ferry, B., Freycon, V., Blanc, L., Desprez, M., Baraloto, C., Chave, J., Descroix, L., Dourdain, A., Guitet, S., Janssens, I.A., Sardans, J., Herault, B., 2017. Nutrient-cycling mechanisms other than the direct absorption from soil may control forest structure and dynamics in poor Amazonian soils. Sci Rep 7, 45017.

Hedin, L.O., Brookshire, E.N.J., Menge, D.N.L., Barron, A.R., 2009. The Nitrogen Paradox in Tropical Forest Ecosystems. Annual Review of Ecology, Evolution, and Systematics 40, 613-635.

Huang, W.Z., Schoenau, J.J., 1997. Seasonal and spatial variations in soil nitrogen and phosphorus supply rates in a boreal aspen forest. Canadian Journal of Soil Science 77, 597-612.

Minz, D., Ofek, M., Hadar, Y., 2013. Plant Rhizosphere Microbial Communities, In: Rosenberg, E., DeLong, E.F., Lory, S., Stackebrandt, E., Thompson, F. (Eds.), The Prokaryotes: Prokaryotic Communities and Ecophysiology. Springer Berlin Heidelberg, Berlin, Heidelberg, pp. 56-84.

Olander, L.P., Vitousek, P.M., 2004. Biological and Geochemical Sinks for Phosphorus in Soil from a Wet Tropical Forest. Ecosystems 7, 404-419.

Qian, P., Schoenau, J.J., 2002. Practical applications of ion exchange resins in agricultural and environmental soil research. Canadian Journal of Soil Science 82, 9-21.

Quesada, C.A., Phillips, O.L., Schwarz, M., Czimczik, C.I., Baker, T.R., Patiño, S., Fyllas, N.M., Hodnett, M.G., Herrera, R., Almeida, S., Alvarez Dávila, E., Arneth, A., Arroyo, L., Chao, K.J., Dezzeo, N., Erwin, T., di Fiore, A., Higuchi, N., Honorio Coronado, E., Jimenez, E.M., Killeen, T., Lezama, A.T., Lloyd, G., 
López-González, G., Luizão, F.J., Malhi, Y., Monteagudo, A., Neill, D.A., Núñez Vargas, P., Paiva, R., Peacock, J., Peñuela, M.C., Peña Cruz, A., Pitman, N., Priante Filho, N., Prieto, A., Ramírez, H., Rudas, A., Salomão, R., Santos, A.J.B., Schmerler, J., Silva, N., Silveira, M., Vásquez, R., Vieira, I., Terborgh, J., Lloyd, J., 2012. Basin-wide variations in Amazon forest structure and function are mediated by both soils and climate. Biogeosciences 9, 2203-2246.

Reed, S.C., Townsend, A.R., Taylor, P.G., Cleveland, C.C., 2011. Phosphorus Cycling in Tropical Forests Growing on Highly Weathered Soils, In: Büneman, E.K., Oberson, A., Frossard, E. (Eds.), Phosphorus in Action: Biological Processes in Soil Phosphorus Cycling, 1 ed. Springer-Verlag, Berlin/Heidelberg, Germany.

Sabatier, D., Grimaldi, M., Prévost, M.-F., Guillaume, J., Godron, M., Dosso, M., Curmi, P., 1997. The influence of soil cover organization on the floristic and structural heterogeneity of a Guianan rain forest. Plant Ecology 131, 81-108.

Sposito, G., 2016. The Chemistry of Soils, third ed. Oxford University Press, New York.

ter Steege, H., Pitman, N.C., Phillips, O.L., Chave, J., Sabatier, D., Duque, A., Molino, J.F., Prevost, M.F., Spichiger, R., Castellanos, H., von Hildebrand, P., Vasquez, R., 2006. Continental-scale patterns of canopy tree composition and function across Amazonia. Nature 443, 444-447.

Turner, B.L., Brenes-Arguedas, T., Condit, R., 2018. Pervasive phosphorus limitation of tree species but not communities in tropical forests. Nature 555, 367-370.

Van Langenhove, L., Depaepe, T., Vicca, S., van den Berge, J., Stahl, C., Courtois, E., Weedon, J., Urbina, I., Grau, O., Asensio, D., Peñuelas, J., Boeckx, P., Richter, A., Van Der Straeten, D., Janssens, I.A., 2019. Regulation of nitrogen fixation from free-living organisms in soil and leaf litter of two tropical forests of the Guiana shield. Plant and Soil.

Vitousek, P.M., 1984. Litterfall, Nutrient Cycling, and Nutrient Limitation in Tropical Forests. Ecology $65,285-298$.

Vitousek, P.M., Sanford, R.L., 1986. Nutrient Cycling in Moist Tropical Forest. Annual Review of Ecology and Systematics 17, 137-167.

Walker, T.W., Syers, J.K., 1976. The fate of phosphorus during pedogenesis. Geoderma 15, 1-19.

Wardle, D.A., Walker, L.R., Bardgett, R.D., 2004. Ecosystem Properties and Forest Decline in Contrasting Long-Term Chronosequences. Science 305, 509-513.

Wright, S.J., 2019. Plant responses to nutrient addition experiments conducted in tropical forests. Ecological Monographs 0, e01382. 
Treatment $\bullet \mathrm{C} \triangle+\mathrm{N} \nabla+\mathrm{NP} \square+\mathrm{P}$
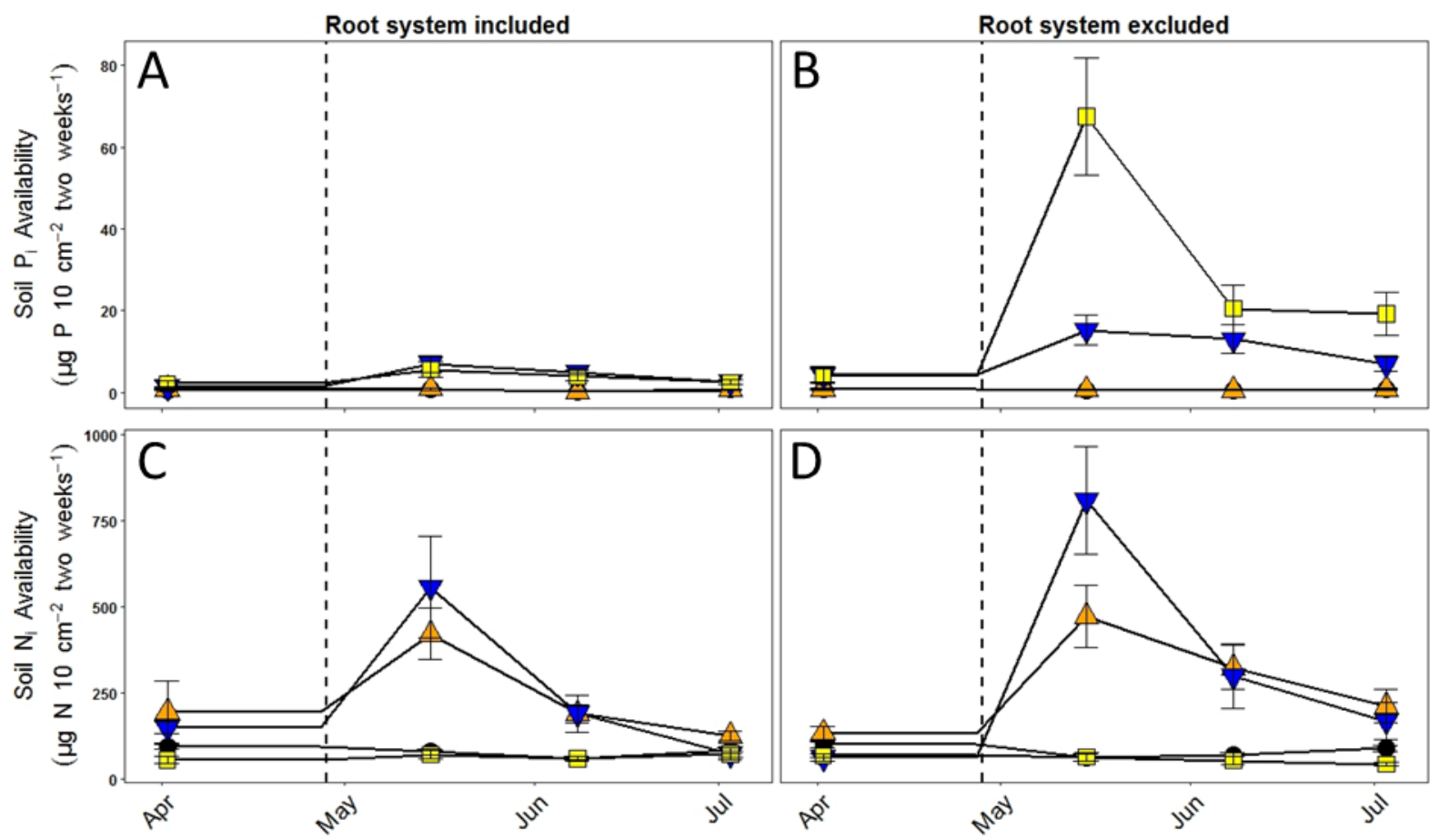

Figure 1 Inorganic $\mathrm{P}$ (top) and $\mathrm{N}$ (bottom) availabilities in the soil in the control treatment (black circle) and before and after in situ fertilization (vertical dashed line) with $+\mathrm{N}$ (red triangle), $+\mathrm{NP}$ (blue triangle) or $+\mathrm{P}$ (green square) fertilizer. Nutrient availabilities were measured four times; one month before fertilization, and four days, four weeks and eight weeks after fertilization. Each measurement of $\mathrm{N}_{i}$ or $\mathrm{P}_{i}$ availability was obtained with PRS probes that were inserted in the soil during 14 days, thus the unit provides the amount of $\mathrm{N}$ or $\mathrm{P}$ in $\mu \mathrm{g}$ that was accumulated on the $10 \mathrm{~cm}^{2}$ ion exchange membrane inside the probe over a 14 days period. Both the availability of $\mathrm{P}_{i}$ and $\mathrm{N}_{i}$ after fertilization in the presence of the root system (top left and bottom left, respectively) and in the absence of the root system (top right and bottom right, respectively) are depicted. Error bars depict standard errors. Twelve plots divided into three blocks each receiving a control, $+\mathrm{N},+\mathrm{NP}$ or $+\mathrm{P}$ treatment were sampled and within a single plot, $N=3$ for each combination of root exclusion treatment and sampling time. 